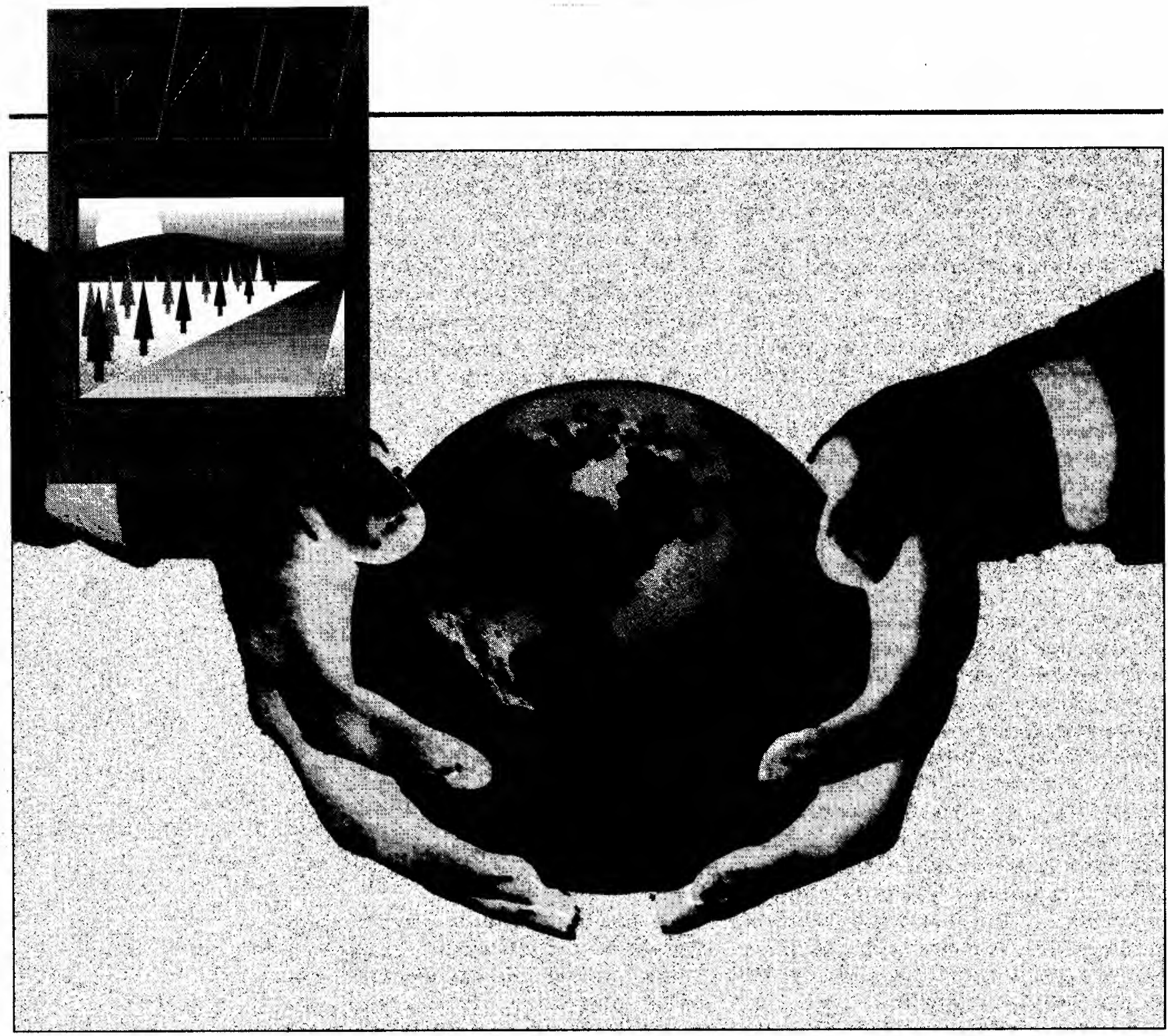

\title{
A VEZ DE UM PACTO PLANETÁRIO *
}

Benedicto Silva

Diretor do CECAPE - Centro de Coordenação das

Atividades de Proteção Ecológica da Fundação

Getúlio Vargas.

* RESUMO: Após a Conferência de Estocolmo, promovida pela Organização das Nações Unidas em 1972, começou a difundir-se no Planeta Terra a conscientização da necessidade vital de preservação do meio ambiente. Nesse mesmo ano, a Fundação Getúlio Vargas deu início à tradução e publicação de seleta bibliografia especializada no assunto. $O$ autor sintetiza em seu artigo a problemática do meio ambiente, primeiro item da agenda mundial, $e$, objetivando o encontro de uma via para o Desenvolvimento Sustentável e o bem-estar geral da humanidade, conclui com a evidência de haver chegado a vez de um Pacto Planetário.

* PALAVRAS-CHAVE: Desenvolvimento Sustentável, Ecologia, explosão demográfica, meio ambiente, pobreza.
* ABSTRACT: After the Stockholm Conference, held by the United Nations Organization in 1972, the awareness of the vital need of the environmental preservation started to spread throughout the planet. At same year, the Getulio Vargas Foundation started the translation and publication of a selected and specialized bibliography on the subject. In his article, the author summarizes the environment problems, first item of the world agenda, aiming to find a path to the Sustainable Development and the general Welfare of the humanity. The author's conclusion is the evidence that a Planetary Pact is now essencial.

* KEY WORDS: Sustainable Development, Ecology, demographic explosion, environment, poverty.

* O texto do presente estudo é uma versão revista e ampliada da conferência, proferida pelo autor, no dia 9 de julho de 1992, a título de abertura do Simpósio Meio Ambiente e Saúde do Trabalhador, então promovido pela Assq̣ciação Brasileira de Medicina do Trabalho.

Săo Paulo, 33(2):64-75 


\section{O PRIMEIRO ITEM DA AGENDA MUNDIAL}

O movimento ambientalista é o primeiro item da Agenda do Planeta Terra. E notório, indiscutivel, que, nos últimos anos, os povos de todos os países se têm preocupado, mais e mais, com as causas $e$ os efeitos da poluição ambiental.

Coube naturalmente à Organização das Nações Unidas institucionalizar o movimento. Para isso, a ONU promoveu, entre várias outras, as medidas seguintes: em 1972, a Conferência de Estocolmo sobre o Meio Ambiente; em 1977, a Conferência de Nairóbi sobre Desertificação, em consequiência da qual criou o Programa das Nações Unidas para o Meio Ambiente; em dezembro de 1983, por força de uma decisão da Assembléia Geral, a Doutora Gro Harlem Brundtland, Primeira-Ministra da Noruega, foi nomeada pelo Secretário Geral das Nações Unidas para constituir e presidir a Comissão Mundial sobre Meio Ambiente e Desenvolvimento.

Tratava-se de um apelo alarmante da Assembléia Geral das Nações Unidas, com a finalidade de:

- propor estratégias ambientais de longo alcance, a fim de obter um desenvolvimento sustentável por volta do ano 2000;

- recomendar maneiras para que a preocupação com o meio ambiente se traduza em ampla cooperação entre todos os países;

- detectar meios e abordagens pelos quais a comunidade internacional possa enfrentar, simultaneamente, e com eficiência, os problemas do desenvolvimento econômico e social e a preservação do meio ambiente.

Observe-se que a Comissão Mundial sobre Meio Ambiente e Desenvolvimento foi constituída por iniciativa e sob os auspícios das Nações Unidas, mas como entidade independente. A responsabilidade de criá-la, porém, foi cometida àquela mulher extraordinária - verdadeiro expoente máximo do gênero humano - que a desempenhou com brilho e exemplar eficiência. Juntamente com o seu Vice-Presidente, Doutor Mansour Chalid, sudanês (exPresidente do Conselho de Segurança das Nações Unidas em 1972), a Doutora
Brundtland prontamente levantou os meios financeiros e selecionou os recursos humanos necessários para compor a Comissão e atacar as respectivas atividades.

Inicialmente, os governos de oito países, Canadá, Dinamarca, Finlândia, Holanda, Japão, Noruega, Suécia e Suíça -

Já foram identificadas e
discutidas as várias causas que
concorrem para a poluição
progressiva do planeta, dentre
as quais se salientam a
explosão demográfica, a
pobreza, a desertificação, o
desmatamento e a emissão de
gases na atmosfera.

os chamados "países patrocinadores" pela Comissão -, propiciaram os recursos financeiros. Paralelamente, os governos de outros oito países, Alemanha (República Federal), Arábia Saudita, Camarões, Chile, Hungria, Itália, Omã e Portugal, fizeram contribuições espontâneas. A Comissão recebeu também contribuições significativas da Fundação Ford, da Corporação Carnegie de Nova York, da Fundação John D. e Catherine MacArthur, da World City Foundation e de várias outras fontes. Sem contar os 15 membros da equipe principal de trabalho e os 14 integrantes da equipe de serviços gerais e de apoio, a Comissão compunha-se de 22 figuras representativas de outros tantos países de todos os continentes.

Os trabalhos da Comissão desenvolveram-se de $1^{\circ}$ de outubro de 1984 a 20 de março de 1987, compreendendo reuniões em Jacarta (Indonésia), Oslo (Noruega), São Paulo e Brasília (Brasil), Vancouver, Edmonton, Toronto, Ottawa, Halifax e Quebeq (Canadá), Harare (Zimbábue), Nairóbi (Quênia), Moscou, Berlim Ocidental, Tóquio e Genebra.

Para ajudá-la em três de suas principais áreas de investigação - energia, indústria e segurança alimentar - a Comissão criou três painéis consultivos integrados por 36 especialistas de renome. 


\section{NOSSO FUTURO COMUM}

Ao cabo de 30 meses de esforços, sondagens, debates, consultas e pesquisas, a Comissão publicou, em abril de 1987, o seu famoso relatório, Nosso futuro comum, o. documento internacional de maipr impacto até então surgido sobre o tema.

A presidente da Comissão abre o prefácio do relatório com o parágrafo seguinte: "Uma agenda global para mudançafoi o que se pediu à Comissão Mundial sobre Meio Ambiente e Desenvolvimento “.

E foi para debater a Agenda Global para a Mudança que as Nações Unidas, com a cooperação das chamadas Organizações Não-Governamentais, convocaram e realizaram, em junho de 1992, no Rio de Janeiro, a maior conferência planetária da história, cujos ecos ainda estão palpitando no noticiário do mundo.

Hoje, às vésperas da passagem do milênio, poucas pessoas haverá que ainda não leram nem ouviram nada sobre as conseqüências pré-catastróficas da poluição ambiental.

Através da palavra escrita e falada, os modernos meios de comunicação - jornais, revistas e, sobretudo, o rádio e a televisão - já possuem tal poder e alcance, que tocam em todos os habitantes de todos os países. Mesmo que esteja em trabalho de mineração a mil metros de profundidade, ou a bordo de uma nave espacial, o homem permanece ligado ao resto do mundo, podendo ouvir, ver e transmitir notícias e imagens. Por outro lado, as informações acumuladas, comprovadas e difundidas sobre as realidades ameaçadoras da sobrevivência da espécie humana são tão sérias, tão inquietantes, que não encontram portas fechadas, afetando praticamente a humanidade inteira.

Já foram identificadas e discutidas as várias causas que concorrem para a poluição progressiva do planeta, dentre as quais se salientam a explosão demográfica, a pobreza, a desertificação, o desmatamento e a emissão de gases na atmosfera.

\section{A POBREZA}

A pobreza é, de longe, a causa mais complexa da poluição do planeta. Por isso mesmo é que o Banco Mundial escolheu
"A Pobreza" como tema título do Relatório sobre o Desenvolvimento Mundial 1990. Com as informações pertinentes de 121 países, de Moçambique (PNB de US\$ 100 per capita) à Suiça (PNB de US\$27.500 per capita), coletadas pelo Banco Mundial, os seus economistas elaboraram um texto de 271 páginas, composto de nove capítulos, 35 gráficos e 45 tabelas.

As causas e os efeitós da pobreza são identificados e analisados ao longo desse documento, formando um cenário inestimável pela riqueza e fidedignidade das informações, variedade dos aspectos focalizados e lógica da análise e das conclusões.

Com efeito, o Relatório descortina a complexidade do tema, repleto de contradições e incertezas. Por exemplo: o trabalho, sem dúvida a principal fonte de produção de riqueza, é também o recurso básico da pobreza. Em princípio, o aumento das legióes de pobres implica necessariamente o aumento dessa insubstituível fonte de produção. Entretanto, tangidos pela insegurança econômica, pelas indignidades da miséria, inclusive pela compulsão da fome, os pobres são forçados a "virar-se", utilizando predatoriamente os recursos naturais.

Por outro lado, a pobreza é a realidade mais dura e desumana do Planeta, porque a sua crueldade recai principalmente sobre os seres mais expostos aos seus efeitos: as crianças e as mulheres.

$\mathrm{Na}$ Visão Geral, capítulo introdutório, - Relatório do Banco Mundial adverte: "Nada poderia ser mais prioritário para as autoridades mundiais do que a redução da pobreza."

Infelizmente, o Brasil ainda permanece na faixa dos países em que predomina a pobreza. O PNB per capita do Brasil tem crescido, mas a renda continua concentrada nas mãos da minoria.

$\mathrm{Na}$ série de relatórios sobre o desenvolvimento, o Banco Mundial focaliza, cada ano, um aspecto distinto do desenvolvimento econômico mundial. Em 1990, o tema foi "A Pobreza"; em 1991, “O desafio do desenvolvimento"; em 1992, “O Meio Ambiente e o Desenvolvimento". No relatório de 1992, as economias nacionais são divididas em quatro níveis de renda per capita (PNB1990), a saber: renda baixa, até US $\$ 620$; 
renda média baixa, de US\$ 621 a US\$ 2.465; renda média alta, de US\$ 2.466 a US\$ 7.620; renda alta, de US\$ 7.621 para cima.

Para se caracterizar bem a situação da pobreza no Brasil, país em desenvolvimento, basta comparar quantitativamente a respectiva distribuição de renda per capita e outros indicadores com os de um país industrializado, como a Suécia, por exemplo.

Com efeito, o confronto exemplificativo de alguns indicadores sócio-econômi$\cos$ da Suécia e do Brasil (ver tabela 1) põe em destaque o contraste da qualidade de vida das respectivas populações.

A Suécia é um país de renda alta, cuja distribuição tende para o igualitarismo: de 1965 para 1989, a participação dos $10 \%$ dos suecos considerados mais ricos baixou de 29 para 21; a dos $20 \%$ considerados ricos baixou de 45 para 37 . Ao passo que, no mesmo período, a participação dos $40 \%$ dos suecos considerados pobres subiu de 15 para 21 ; e dos $20 \%$ considerados mais pobres subiu de 5 para 8 .
O Brasil já é classificado como país de renda média alta. Apesar disso, a distribuição de sua renda continua extremamente desigual. Não há dados referentes a 1965. Em 1989, porém, a participação dos $10 \%$ dos brasileiros considerados mais ricos foi de 46 ; a dos $20 \%$ considerados ricos, 63 ; a dos $40 \%$ considerados pobres, 8 ; e a dos $20 \%$ considerados mais pobres, apenas 2 .

Atente-se para os contrastes seguintes: no ano em apreço, 1989 , aos $20 \%$ dos mais ricos tocaram, respectivamente, $37 \%$ e $63 \%$ do PNB na Suécia e no Brasil. Ao passo que, na mesma ordem, tocaram $8 \%$ aos mais pobres na Suécia e apenas $2 \%$ no Brasil.

Embora ainda existam na Europa e no Oriente Médio vários países de renda média anual per capita inferior a US\$ 2.500 , como a Síria, a Turquia, a Romênia e a Polônia, é nos países da África subsaariana, do Leste e Sul da Ásia, do Norte da África e da América Latina que se concentra a pobreza.

Somadas, as populações dos 43 países

\section{Tabela 1:}

\section{Brasil e Suécia: indicadores básicos}

\begin{tabular}{|c|c|c|c|c|}
\hline \multirow{2}{*}{$\begin{array}{l}\text { Indicadores } \\
\text { sócio-econômicos* }\end{array}$} & \multicolumn{2}{|c|}{ Suécia } & \multicolumn{2}{|c|}{ Brasil } \\
\hline & 1965 & 1989 & 1965 & 1989 \\
\hline $\begin{array}{l}\text { 1. Renda média per capita } \\
\text { em US\$ }\end{array}$ & 2.740 & 21.710 & 270 & 2.540 \\
\hline \multicolumn{5}{|c|}{$\begin{array}{l}\text { 2. Distribuição percentual da renda } \\
\text { por grupos }\end{array}$} \\
\hline Os $10 \%$ mais ricos & 29 & 21 & - & 46 \\
\hline Os $20 \%$ ricos & 45 & 37 & - & 63 \\
\hline Os $40 \%$ pobres & 15 & 21 & - & 8 \\
\hline Os $20 \%$ mais pobres & 5 & 8 & - & 2 \\
\hline 3. Expectativa de vida (anos) & 73,9 & 77,4 & 57,9 & 68,6 \\
\hline 4. № de habitantes por médico & 910 & 387 & 2.500 & 1.080 \\
\hline $\begin{array}{l}\text { 5. Mortalidade Infantil } \\
\text { por mil habitante }\end{array}$ & 13,3 & 5,6 & 103,6 & 59,9 \\
\hline 6. Ingestão diária de calorias & 2.880 & 3.007 & 2.415 & 2.709 \\
\hline
\end{tabular}

*World Bank. Social indicators of development 19g0. Baltimore, London, Johns Hopkins University Press, 1991. Páginas 40-1 (Brasil) e 296-7 (Suécia). 
classificados pelo Banco Mundial como "economias de baixa renda", isto é, renda média anual per capita de até US\$ 620 , totalizam 3.058,3 milhões de seres humanos, mais da metade da população mundial.

Fazem parte desse grupo de países a China, com 1.133,7 milhōes de habitantes, a Índia, com 849,5 milhões, a Indonésia, a Nigéria, o Paquistão e Bangladesh, cada qual com mais de 100 milhöes, e mais 37 países de populações menores, todos asiáticos ou africanos, com as únicas exceções do Haiti e Honduras, que pertencem à América Latina. É claro que há famílias e indivíduos ricos, até milionários, em todos eles, mas a maioria absoluta é formada de pobres.

As informações constantes desse documento demonstram que é possível combater a pobreza de modo rápido, politicamente sustentável, mediante uma estratégia composta de duas práticas de suma e igual eficácia:

a. a utilização produtiva do trabalho, o principal bem de que os pobres dispõem;

b. a prestação de serviços básicos aos pobres, em especial atendimento médico, planejamento familiar, nutrição, educação primária, abastecimento de água e saneamento.
Tal estratégia, aliás, já está sendo implementada em alguns países - na Indonésia e na Malásia, por exemplo - propiciando melhoria de condiçôes de vida aos pobres. $O$ investimento em serviços de saúde e educação permite-lhes aproveitar plenamente as oportunidades assim criadas.

No Brasil também houve aumento de produtividade, mas ainda não se deu a devida expansão aos serviços de saúde e educação.

\section{A DESERTIFICAÇÃO E O DESMATAMENTO}

O reino vegetal é a principal fonte de recursos insubstituíveis de que a espécie humana depende para sobreviver. Desde que o mundo é mundo, a mãe natureza está à disposição do homem, prodigalizando-lhe ervas, folhas, plantas, flores, cereais, frutas, cascas, lenha, madeira para fins de alimentação, aquecimento, tratamento de saúde, vestuário, fabricação de móveis, utensílios, construção de moradias, locais de trabalho etc.

Imemorial e universal, essa prática só recentemente começou a chamar a atenção dos observadores, movidos pelas notícias da desertificação e do desmatamento de áreas cada vez mais extensas em todos os continentes. Foi assim, quase repentinamente, que surgiu a ameaça da hecatombe ambiental.

Sem especificar a superfície total de terras já desertificadas, nem a superfície total de terras já desmatadas, o relatório Nosso futuro comum indica, quantitativamente, os milhões de hectares de terras produtivas transformados em desertos, bem como os milhões de hectares de florestas abatidos, cada ano.

A fim de demonstrar as proporçóes e o avanço da desertificação, o Relatório apresenta os seguintes dados: a cada ano, 6 milhões de hectares de terras produtivas são transformados em desertos estéreis. Significa isso que, em 30 anos, a área desertificada cobrirá 2.170 .000 quilôme- 


\section{Gráfico 2 - Desmatamento}

Milhões de hectares

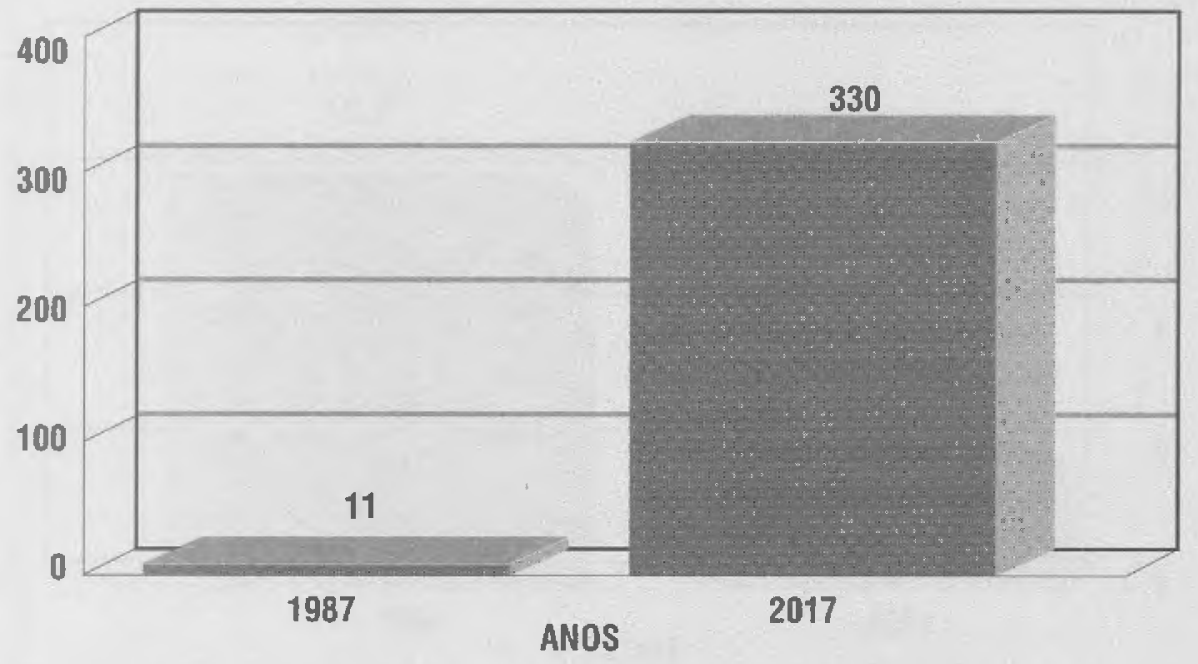

tros quadrados, o que corresponde à soma dos territórios de seis países europeus Alemanha Federal (antes da reunificação), Espanha, França, Inglaterra, Itália e Noruega. Parece incrível, mas é verdade documentada. (Ver gráfico 1).

Similarmente, para descrever o desmatamento, o mencionado Relatório publica dados não menos estarrecedores: anualmente, são destruídos mais de 11 milhões de hectares de florestas o que, após o mesmo prazo de 30 anos, representará uma área igual à da Índia: cerca de 3.300 .000 quilômetros quadrados. (Ver gráfico 2).

\section{O EFEITO ESTUFA}

Quanto à emissão de gases e o efeito estufa, as informações - demasiado numerosas, complexas e descritas em linguagem científica - não se prestam a resumos e gráficos estatísticos.

Todavia, sabe-se que só as emissões de dióxido de carbono, o maior causador do efeito estufa, aumentaram de cerca de 1 bilhão e 800 milhões para cerca de 5 bilhões e 800 milhões de toneladas no período de 1950 a 1980 . (Ver gráfico 3).

A fonte mais autorizada de informaçōes sobre o assunto é o livro Aquecimento global, contendo 19 capítulos de autoria de 20 cientistas de renome internacional, entre os quais figura o Professor José Goldem- berg, ex-Ministro da Educação do Governo Federal do Brasil. O livro comprova que o aquecimento global representa uma alteração do meio ambiente sem paralelo na experiência humana.

Em virtude do efeito estufa, a temperatura do planeta está-se tornando mais elevada, sobretudo na segunda metade do século XX. Por sua vez, o aumento da temperatura tende a provocar o degelo das calotas polares e glaciais e a conseqüente elevação do nível do mar. De acordo com as indicações do livro S.O.S. Planeta Terra, do citado cientista José Goldemberg, ao longo do século passado e até 1940, o nível do mar subiu pouco mais de $1 \mathrm{~cm}$ por decênio. A partir daquela data, porém, passou a subir cerca de $6 \mathrm{~cm}$ por decênio. Se tal elevação continuar, no ano 2050 o nível do mar terá subido de 0,75 a $1,50 \mathrm{~cm}$, afetando catastroficamente alguns países, como a Holanda e Bangladesh, assim como todas as cidades litorâneas. Se isso acontecer, o nosso Rio de Janeiro, a cidade maravilhosa, ficará reduzido às favelas.

\section{A EXPLOSÃO DEMOGRÁFICA}

Mas a causa das causas da poluição ambiental é o vertiginoso aumento da população. Segundo os registros diponíveis, a população mundial, no ano 1000 


\section{Gráfico 3 - Emissão de dióxido de carbono}

Bilhões de toneladas

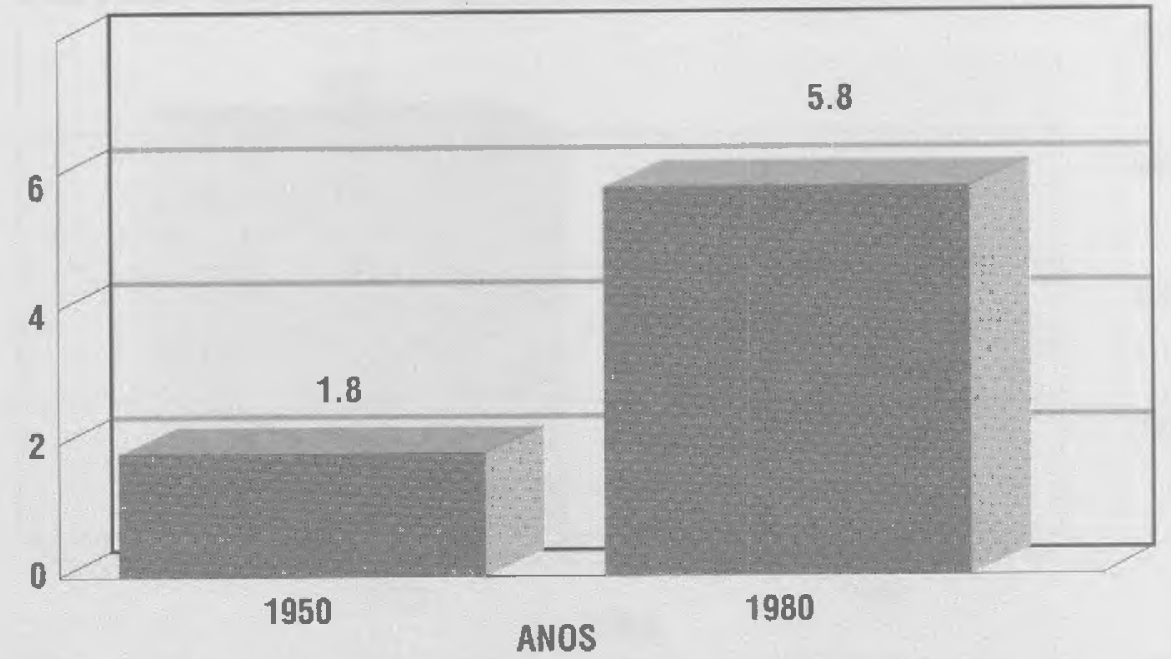

da Era Cristã, teria chegado a 340 milhões. Oito séculos e 80 anos depois, em 1880 , subiu para 1 bilhão, isto é, mil mi1hões. Mas, apenas 48 anos depois, em 1928 , já se havia duplicado, chegando a 2 bilhões, passando para 3 bilhões em 1960, para 4 bilhões em 1975, para 5 bilhões em 1986, devendo chegar a 6 bilhões e 100 milhões no ano 2000. Para se formar uma idéia mais clara do ritmo de aumento da população, basta medi-lo em termos de dias, a saber: do ano 1000 ao ano 1880 , decorreram 324.200 dias ( 880 anos); de 1880 a 1928 , decorreram 17.520 dias ( 48 anos); de 1928 a 1960 , decorreram 11.680 dias (32 anos); de 1960 a 1975 decorreram 5.475 dias (15 anos); de 1975 a 1986, decorreram 4.015 dias (11 anos); de 1986 a 2000 terão decorrido 5.110 dias (14 anos).

Cumpre arrolar e, tanto quanto possível, dimensionar aqui a realidade seguinte: os fenômenos de repercussão mundial ocorridos, alguns em cadeia precipitada, outros simultaneamente, ao longo dos últimos 100 anos, conferem ao século XX o destaque de período mais dramático da História. Basta indicar que, no curso de apenas 76 anos, de 1914 a 1990, explodiram a Primeira Guerra Mundial, a Revolução de Outubro de 1917, a Segunda Guerra Mundial, inventou-se a bomba atômica, criou-se a Organização das Nações Unidas, a Informática transformou o mundo em Aldeia Global, o homem pousou na Lua, houve a Guerra Fria, emergiu a Comunidade Econômica Européia, - Muro de Berlim foi derrubado e a União das Repúblicas Socialistas Soviéticas se auto-implodiu.

Mas o acontecimento dominante é, sem dúvida, a quintuplicação da população mundial, que subiu de 1 bilhão em 1880 para 5 bilhões em 1986, estimandose que chegará a 6,1 bilhões no ano 2000 . (Ver gráfico 4).

Dado o ritmo em que aumentam a população mundial, o desmatamento, a desertificação, a emissão de gases e a poluição dos mananciais e da atmosfera, cabe a indagação apocalíptica: por quanto tempo mais os recursos do planeta serão suficientes para agüentar a carga de manter a espécie humana?

\section{O TRABALHO}

Só o trabalho produz valor, eis o axioma revolucionário do marxismo. Não é meu propósito, menos ainda minha tarefa, discutir aqui o postulado em que Karl Marx se baseou para formular o conceito teórico da mais valia, de que resulta, segundo a análise marxista, a exploração do homem pelo homem, isto é, do homem trabalhador pelo homem capitalista. 
Hoje, relativamente à teoria marxista, não se pode deixar de levar em conta dois fatos históricos antagônicos.

No começo do século $X X$, o impacto de convicção do marxismo era tão poderoso que catapultou, em 1917, a Revolução de Outubro e o surgimento da União das Repúblicas Socialistas Soviéticas, sob a liderança de Lênin.

A súbita auto-implosão do Colosso Soviético, em 1990, praticamente pôs por terra o Marxismo e todas as suas ramificaçōes e estratégias - o Bolchevismo, o Leninismo, o Trotskismo, o Maoísmo, a Estatização Maciça, a Revolução Permanente, o Socialismo num só país, inclusive a crença na inevitabilidade do Comunismo Anárquico.

Todavia, ainda não há razões para se afirmar categoricamente que a luta da teoria marxista contra o sistema capitalista haja cessado, ou sequer mostrado tendência a cessar, em futuro previsível. Ao contrário, as ideologias adversas, de esquerda e de direita, continuam presentes e vivas na marcha da História.

Parecem-me cabíveis, entretanto, algumas observaçōes gerais sobre o trabalho como fator principal da produção de utilidades e serviços que sustentam a sobrevivência e possibilitam o bem-eștar da espécie humana.
A busca da racionalização do trabalho e da dignificaçāo do trabalhador é um fruto positivo da civilização, do qual decorrem normas que aumentam a eficiência do trabalhador e, ao mesmo tempo, reduzem o tempo de trabalho. Não é preciso recuar a épocas longínquas para se constatar os efeitos da tendência, a que podemos chamar de diminuinão da jornada de trabalho.

Com efeito, em época relativamente recente, a duração do tempo de trabalho escravo era ilimitada e a do trabalho livre dividida em semana de seis dias e jornada de 12 horas, de "sol a sol", como se dizia então. Já no curso do século XX, em muitos países, a semana de trabalho passou. para cinco dias e a jornada baixou para oito horas e, atualmente, em alguns casos, para seis horas.

A diminuição da semana de trabalho de seis para cinco dias e da jornada de 12 para oito horas representa uma preciosa conquista da civilização em benefício do trabalhador e de toda a comunidade humana.

Creio que não pecarei por exagero se proclamar o trabalho como o mais poderoso fator da civilização. A natureza é o celeiro das matérias-primas. A ciência é o laboratório do conhecimento. A tecnolo-

\section{Grático 4 - População}

População em bilhões

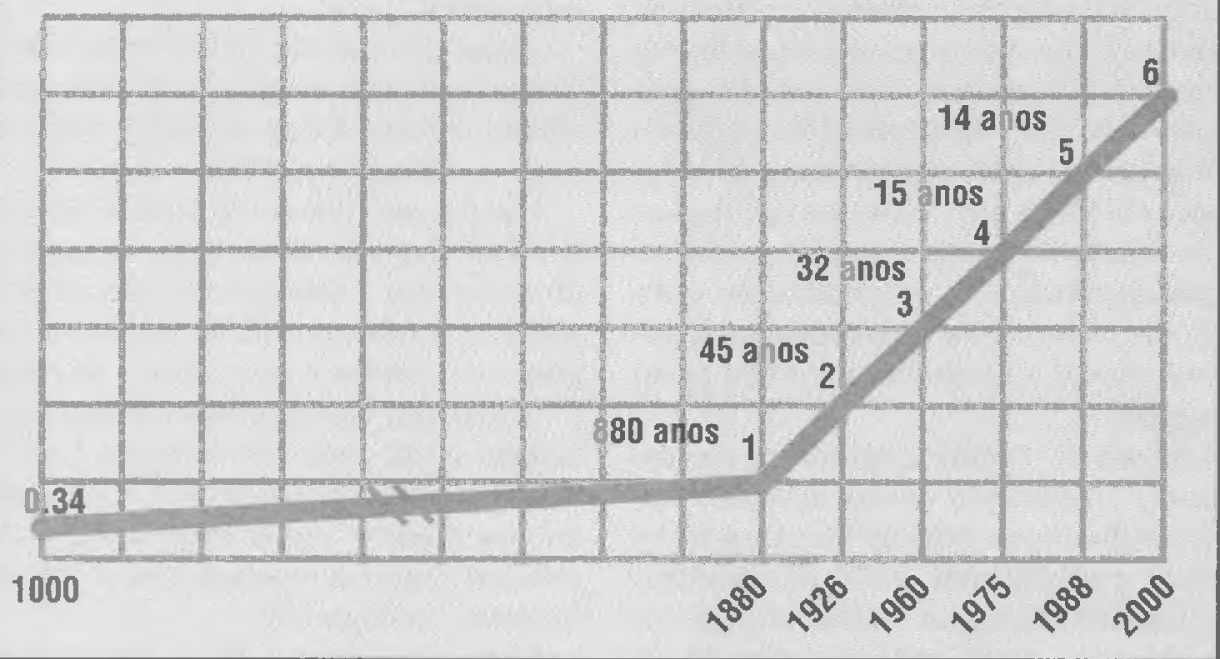


gia é o processo de aplicação racional dos resultados da ciência. Mas é o trabalhador que move as matérias-primas, realiza a pesquisa científica e aplica a tecnologia.

\section{TAYLOR E A RACIONALIZAÇÃO DO THABALHO}

A propósito da racionalização do trabalho, uma das ocorrências mais conseqüentes do desenvolvimento econômico mundial, seja-me permitido invocar a personalidade fascinante de Frederick Winslow Taylor. Em virtude de uma deficiência visual, ocasionada por leituras, Taylor foi impedido de seguir a carreira do pai, a advocacia.

Embora filho de família abastada, começou a trabalhar como operário. Em 1874 , aos 18 anos de idade, Taylor entrou como aprendiz de torneiro e maquinista para uma fábrica de bombas hidráulicas. Quatro anos depois, já senhor do ofício, foi admitido como simples operário na usina de Mildvale Steel Company, em que fez carreira rápida, galgando sucessivamente os postos de apontador, chefe de turma, assistente de contramestre, mecânico-chefe, desenhista-chefe e engenheiro-chefe.

O desempenho dessas atividades, notadamente a de chefe de turma, inspiroulhe as primeiras idéias sobre os aspectos mais importantes do trabalho: o desperdício, os movimentos inúteis, a padronização das tarefas e a análise de tempo e movimento.

Em 1880, Taylor matriculou-se num instituto para fazer, in obsentia, o curso de engenheiro-mecânico, grau que, graças a extensas horas noturnas de estudo, conquistou em 1883. Sua elevação ao posto de engenheiro-chefe das oficinas da Siderúrgica de Mildvale deu-se pouco depois da conclusão do curso. Como se vê, a formação do criador da administração científica não ocorreu na universidade, ocorreu na oficina. $O$ trabalho foi o seu grande mestre.

A figura de Taylor agiganta-se na história da civilização como inventor social. Coube-lhe a criação de uma nova carreira profissional, a de administrador, fato amplamente conhecido em todo o mundo e focalizado em numerosos livros, revistas e jornais.
O que, da obra de Taylor, até agora não tem sido objeto de maior divulgação e comentário é o que podemos chamar de antecipada preocupação ambientalista. Com efeito, Taylor denunciou, em 1911, na introdução de seu livro Princípios de administração científica, publicado à sua custa, fatos que hoje estấo na ordem do dia da Agenda Mundial Seja-me permitido repetir, ipsis literis, os seguintes parágrafos do referido texto: "Sabemos que nossas florestas estão desaparecendo, vemos nossas quedas d'água desperdiçadas, nosso humus varrido pelas enchentes e carregado para o mar; $e$ o fim de nossas reservas de carvão e de minério de ferro já está à vista."

Isso foi publicado, notem bem, em 1911. Inimigo do desperdício, Taylor foi um dos primeiros ambientalistas do século. Aliás, a eficiência, que é o oposto do desperdício, consiste em produzir o máximo com o mínimo de esforço.

\section{O DESENVOLVIMENTO SUSTENTÁVEL}

A melhoria geral da qualidade de vida está implícita no chamado desenvolvimento sustentável. Para se conquistar esse objetivo, é indispensável tornar acessíveis, a todas as camadas sociais, a posse, o uso e o consumo dos bens e serviços necessários à boa vida. No sentido aristotélico, o conceito de boa vida pressupõe a existência de uma conjuntura econômica e social que garanta, a todos os habitantes do planeta, condições satisfatórias de habitação, alimentação, assistência médico-hospitalar, educação, emprego, turismo e lazer.

Acontece que, de todos os fatores que concorrem para o estágio de desenvolvimento sustentável, o trabalho bem ordenado é o mais produtivo.

Lembre-se que $A$ Declaração Universal dos Direitos Humanos determina minuciosamente: "toda pessoa tem direito ao trabalho, à livre escolha do mesmo, a condiçōes equivalentes e satisfatórias de trabalho $e$ à proteção contra o desemprego... a um salário igual para um trabalho igual... a uma remuneração eqüitativa e satisfatória que lhe assegue, assim como à sua familia, uma existência compatível com a dignidade humana." (artigo 23).

Mas, não é apenas por motivos éticos e humanitários que a sociedade deve aqui-
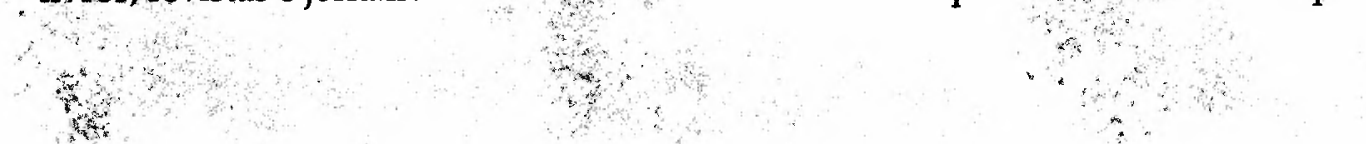
nhoar bem o trabalhador. Tudo quanto fizer em seu benefício, garantindo-lhe um nível de vida decente, contribui para o desenvolvimento sustentável. $\mathrm{Na}$ atual conjuntura histórica, cumpre agregar às razões humanitárias o problema do planejamento da utilização dos recursos naturais, que emergiu como prioridade mundial dominante. Salta a vista que o aumento do poder aquisitivo do traba-

\section{Desde a promulgação de sua} Carta Magna, em 1988, o Brasil já está constitucionalmente engajado no combate à devastação do meio ambiente. Tal compromisso consta explicitamente de vários artigos da Constituição.

lhador não impede, antes impulsiona, o desenvolvimento sustentável. $O$ trabalhador saudável, bem aquinhoado em matéria de salário e de segurança econômica, bem treinado e consciente do dever de proteção do meio ambiente, é um produtor natural de ordem e progresso. As práticas de proteção do meio ambiente e a melhoria da qualidade de vida do trabalhador são totalmente compatíveis.

Dar assistência plena aos inválidos é praticar justiça social. Dar assistência plena aos velhos é solidariedade humana. Dar assistência plena às crianças é assegurar o futuro da espécie humana. Dar assistência plena aos operários é lógica econômica, porque estimula a produção de riqueza.

Assim, o desenvolvimento sustentável depende essencialmente do trabalho. Não pairam dúvidas de que a utilização planejada dos recursos naturais gera muito mais trabalho. Até hoje, a finalidade do trabalho tem sido principalmente produzir alimentos, facilidades, utensílios e serviços para atender às necessidades vitais do homem. De agora em diante, com a deterioração assustadora do meio ambiente, o trabalho terá igualmente a finalidade de proteger e garantir a existência dos recursos renováveis e reciclar os recursos minerais e aquáticos em todos os cantos do mundo. Imagine-se o colossal volume de trabalho, praticamente imensurável, necessário só para reparar os danos já feitos - reflorestamento, recuperação de áreas tornadas desérticas, reconstrução de ambientes urbanos, restauração de habithats naturais e aproveitamento de terras selvagens. Se tudo isso for empreendido, não haverá desemprego. Ao contrário, haverá insuficiência de trabalhadores.

\section{O SINDICALISMO}

Tratando-se do tema Sindicalismo, parece-me oportuno repetir alguns parágrafos de texto de minha modesta autoria, publicado em 1989.

A luta pela melhoria das condições de vida dos trabalhadores vem de longa data. Depois de adotar ou receber denominações várias e passar por diversas fases radicais, sob a influência de ideologias conflitantes, esse movimento veio a ser chamado Sindicalismo, nome hoje consagrado pelo uso.

Nascido na Inglaterra por volta de 1720 , o movimento manteve-se em fase embrionária, desenvolvendo-se lentamente ao longo do século XIX. No início do século XX o movimento tornou-se mais ativo, na Europa e nos Estados Unidos, atraindo a adesão de milhares e milhares de trabalhadores, inclusive de grupos religiosos. O Partido Operário Católico, por exemplo, surgido na Bélgica em 1902, é uma prova da presença de religiões nesse movimento.

Ninguém pode questionar a grande contribuição das reivindicações sindicalistas pró-desenvolvímento econômico e social, de um lâdo, e contra as injustiças do sistema de salários e das más condições de trabalho, de outro. Trata-se de uma evidência histórica meridiana, comprovada por dezenas de elos da cadeia de estágios do conflito Sindicalismo versus Capitalismo.

Embora o Sindicalismo geralmente seja concebido e rotulado como "luta de classes" - luta da classe dos trabalhadores contra a classe dos patrões - é preciso reconhecer que as suas sucessivas vitórias não resultaram de guerra campal,
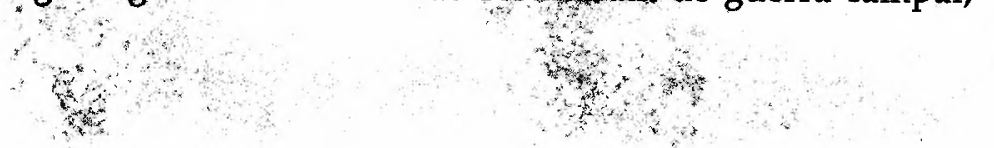
mas do compasso da civilização. Foi em conseqüiência da civilização que o Sindicalismo conquistou, na maioria dos países capitalistas, entre muitas outras garantias, o direito de greve. Como o Cooperativismo, como a Cruz Vermelha, o Sindicalisnơ êuma invenção social filantróspica, uñ produto da civilização. E no uso do direito de greve, sobretudo no uso $60 \mathrm{~s}$ direitos fundamentais do homem, que o Sindicalismo vem conquistando para os trabalhadores não apenas maiores parcelas de bens materiais e de segurança econômica, mas também mais espaço nos meios políticos e na sociedade em geral.

Talvez a mais valiosa conquista do Sindicalismo seja a influência ascensional dos trabalhadores nas decisões e no próprio destino das empresas. Há notícias fidedignas sobre diversas instâncias em que importantes sociedades anônimas passaram a ser dirigidas por comitês dos respectivos empregados. A civilização parece tender a democratizar progressivamente a empresa, estimulando-a a fazer de cada empregado, do mais simples ao mais graduado, um sócio acionista.

Paralelamente, o avanço da ciência e da tecnologia tem concorrido e continua a concorrer para a melhoria das condições de vida dos trabalhadores. Salários melhores, férias remuneradas, assistência médico-hospitalar, escolas profissionalizantes, aumento da produtivade e conseqüente diminuição da semana e da jornada de trabalho, oportunidades mais frequientes de lazer, eis os benefícios atualmente garantidos a milhões de trabalhadores espalhados por todos os continentes, engajados nas empresas, das macro às micro.

$€$ indisputável que tais benefícios se tornaram viáveis graças não apenas às reivindicações do Sindicalismo, más, sobretudo, ao progresso da ciência e da tecnologia. Observe-se, ademais, que os bens e frutos gerados pela ciência e pela tecnologia não são suscetíveis de discriminação. Como o sol, nascem para todos.

\section{O BRASIL E A DEFESA AMBIENTAL}

Desde a promulgação de sua Carta Magna, em 1988, o Brasil já está constitucionalmente engajado no combate à devastação do meio ambiente.
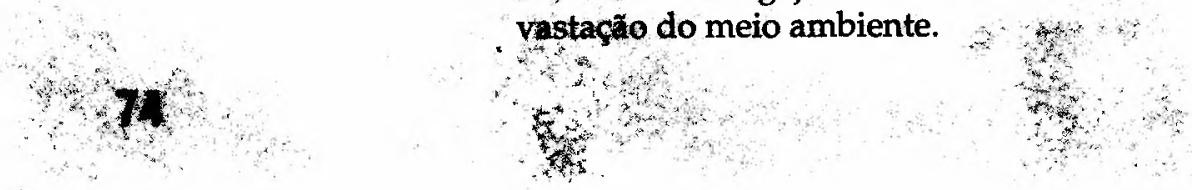

Tal compromisso consta explicitamente de vários artigos da Constituição.

Segundo os artigos 23 e 24 , por exemplo, a defesa do meio ambiente - isto é, a conservação da natureza e a proteção dos recursos naturais - é de competência comum da União, dos estados, do Distrito Federal e dos municípios cabendo-lhes legislar sobre a matéria 08 artigos $170 \mathrm{e}$ 174 igualmente atribuem ao Estado, em sua condição de agente normativo e regulador da atividade econômica, a função de garantir a defesa do meio ambiente. Por último, diz o artigo 225: "Todos têm direito ao meio ambiente ecologicamente equilibrado, bem de uso comum do povo e essencial d̀ sadia qualidade de vida, impondo-se ao Poder Público e à coletividade o dever de defendê-lo e preservá-lo para as presentes $e$ futuras gerações." Ainda segundo o artigo, para assegurar a efetividade desse direito, entre outras coisas, incumbe ao Poder Público:

- "preservar os processos ecológicos essenciais e a integridade do patrimônio genético do país;

- definir os espaços territoriais a serem especialmente protegidos;

- exigir estudo prévio de impacto ambiental das atividades potencialmente nocivas ao meio ambiente;

- promover a educação ambiental em todos os níveis de ensino e a conscientização pública para a preservação do meio ambiente."

Também são previstas, no parágrafo $3^{\circ}$ do mesmo artigo, sanções penais e administrativas para as condutas e atividades consideradas lesivas ao meio ambiente.

\section{O COMPROMISSO AMBIENTALISTA DA FGV}

E igualmente oportuno informar que a Fundação Getúlio Vargas, de cujo quadro de servidores faço parte desde 1950, sempre se bateu, sobretudo por meio de dezenas de publicações, pela conservação da natureza (ver Bibliografia anexa).

E a partir de 1991, uma de suas finalidades estatutárias passou a ser precisamente "...contribuir para a proteção ambiental e o desenvolvimento sustentável".

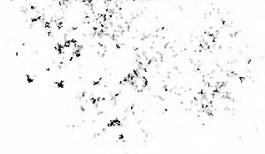




\section{A VEZ DE UM PACTO PLANETÁRIO}

Estou convencido de que, para enfrentar a ameaça da hecatombe ecológica, os povos de todos os países do mundo têm que pactuar uma unanimidade de compromissos sem paralelo. Até hoje nenhuma preferência ideológica, religiosa, étnica, filosófi- ca ou racista logrou unir a humanidade.

Alimentemos a esperança de que o ideal do desenvolvimento sustentável extinção da pobreza e preservação do meio ambiente - consiga levar todos os seres humanos, de mãos dadas, a aprovar e cumprir o Pacto Planetário de Seguro da Humanidade. 4 ,

$$
\text { a }
$$

\section{BIBUOORAFIA ESPECINLZMU SOBRE OTIEDO AMBIEUTEE DESEWVOLVMENTO}

1. THANT, $U$. et ali, Guerra poluicto, Rio de Jàneiro: Fun daçấ Getulio Vargas. 1973 $96 \mathrm{p}$ :

2. KADE, Gerhard et ali, O ho men $\varepsilon$ seu ambiente. Rio de Ja neiro: FGV, $1975,316 \mathrm{p}$

3. VILA, Rafael Caniel. Os se sedos do tempo. Rla de Janeiro RGV, $1975,143 \mathrm{p}$ :

4. BROWN, Lester Russell. O vigésimo-riono dia: a terra empobrece: e preciso ajustar-se à coerencie e parar de crescer. Rio de Janeiro: FGV, $1980,310 \mathrm{p}$.

5. DUPUY, Jean Pierre. Intro duçäo de critica da ecologia politica. Rio de Janeiro: Civilização Brasileira, 1980, 112 p.

6. MAGALHÃES, Juraci Peres. Recursos Naturais, meio ambiente e sua defesa no direito brasileiro. Rio de Janeiro: FGV, 1982, $76 \mathrm{p}$.

7. NEGRET, Rafael.Ecossistema: unidade básica para o planejamento da ocupaçăo territorial. ecologia e desenvolvimento. Rio de Janeiro: FGV, 1982, 99 p.

8. COMISSÃO MUNDIAL SOBRE MEIO AMBIENTE E DESENVOLVIMENTOO. Nosso futuro comum. Rio de Janeiro: FGV, 1988, 430 p.

9. ANCHIETA, José de. Cartas Inéditas/Padre José de Anchieta. Rio de Janeiro: FGV, 1989, $69 \mathrm{p}$.

10.BRUNDTLAND BULLETIN. The Brundtland Report Spring 1989 - From grassroots to summits - and back. Geneva: The Centre for Our Common Future, $n^{6} 3$, Mar. 1989 , $70 \mathrm{p}$

11. International TV triumph for "Our Common Future" as the momentum for change builds. Geneva: The Centre for Our Commom Future, $n^{2}$ 4, Jul. 1989, $93 \mathrm{p}$

12 -Working towards our common future: new book will explore signis of hope and chart the way forward Ceneva: The Centre for Our Common Future, $n^{*} 5$, Sept. 1989 , $117 \mathrm{p}$.

13. Un general Assembly meets to finalize the 1992 Conference as envitonment and development come in from the cold in Eastern Bu: rope. Geneva: The centre for Our Commom Future, n: 6 , dez. 1989, 118 p.

14. CHILAvENATO, Jálio Jose. O massacre da natureza. Sa. Paulo: Moderna, 1989, 136 p:

15. BRUNDTLAND BULLETIN. Key 1992 roles for strong and koh top appointments boost hopes for outcome of World Conference. Gerieva: The Centre four Our Commom Future, $\mathrm{n}^{\mathrm{2}} 7$, Mar. 1990, $118 \mathrm{p}$.

16. - Action for a Com mon Future: Bergen Conference points a new way forward. Geneva: The Centre for Our Commom Future, $n^{*} 8$, june $1990,123 \mathrm{p}$.

17. Geneva: The Centre for Our Common Future, $n^{2}$ 9/10, Sept./Dec. 1990, 144 p. Número especial.

18. GOLDEMBERG, José. S.O.S. Planeta Terra: o efeito estufa. Sấo Paulo: Brasiliense, $1990,72 \mathrm{p}$

19. MAYOR, Federico. Ananha sempre é tarde. Rio de Janeiro: FGV, $1990,288 \mathrm{p}$.

20. TORRES, Alberto. As fontes da vida no Brasil. Rio de Janeiro: FGV, $2^{a}$ ediçẫo, 1990,32 p.

21. BRUNDTLAND BULLETIN. Geneva: The Centre for Our Commom Future, $n^{2} 11$ Mar. 1991, $\mathrm{n}^{\circ} 12$, June 1991; $\mathrm{n}^{2}$ 13, Sept. $1991,90 \mathrm{p}$.
22. IAGUARIBE, Hélio. As Naçdes Unidas e a reestruturaçăo da ordem mundial. $R e$ vista de Adininistractöo Publica. Rio de Janeiro. $\nabla .25, n^{\circ} 3,0.5$ 16; Jul. / Set 1991 (Discurso proferido na celebracto da Se mana das Naçóes Unidas, em 22,10.90.

23. BANCO MUNDLAL Relatorio sobre o deservolvimento. mindial 1991 * desafio do desenvolvimento. Rio de Janeiro: $\mathrm{FGV}, 1991,313 \mathrm{p}$.

24. MOLTKE, Konrad von. Global environment - a planet in stress. In: 1991 Britannica book of the year. Chicaro Enc. Britannica, 1991, p. 5-14.

25. STARKE Linda. Sinais de esperanga: litando por nosso futuro comum. Rio de Janeiro: $\mathrm{FGV}_{i}$ 1991, $180 \mathrm{p}$.

26. AOUECIMENTO Global: O Relatório Greenpeace/Editor responsdvel Jeremy Leggett: Rio de Janeiro: FGV; $1992 ; 516$ p.

27. BANCO MUNDIAL. Relatório sobre o desenvolvimento mundial 1992: desenvolvimento e meio ambiente. Rio de Janeiro: FGV, 1992, 352 p.

28. BRUNDTLAND BULLETIN. Special Earth Summit issue. Geneva: The Centre for Our Common Future, n' 16 , July $1992,99 \mathrm{p}$.

29. MEIO AMBIENTE e desenvolvimento: a pacto planetário. O Correio da Unesco. Rio de Janeiro, v. $20, n^{\circ} 1, p .4-45$ jan. 1992.

30. SALVAR o meio ambiente. Finanças \& Desenvolvimento. Rio de Janeiro, v. 12, $n^{2} 2$, p. 2 47, jun. 1992.

31. O UNIVERSAL é europeu? O Correio da Unesco. Rio de Janeiro, v. 20, $n^{2} 9 / 10$, p. 1-66, set./out. 1992.

32. A POLITICA ambiental e desenvolvimento: um tema para a cooperaçắo - Umweltpolitik und entwicklung: ein thema zur kooperation. Brasí lia, DF DMF Congressos, Planejamento e Assessoria, $(1991), 301 \mathrm{p}$

33. SCHMMDHEINY, Stephan. Mudando o rumo: uma perspecti on empresarial global sobre de senvolvintento $\mathrm{E}$ meio ambiente. Rio de laneiro: FGV, 1992 $368 \mathrm{p}$.

34. BRANCO, Samuel Murgel O meio ambiente en debate. Săo Paulo: Moderna

35. BRIGAGAO, Clóvis A cor rida para a morte. Rio de Janei. ro: Nova Fronteira.

36. CARSON, Rachel Primave na silericiosa. São Paulo: Melho ramentos.

37. CONII, Laura. Ecologia. Saio Paulo: HUCITEC

38. DUMONT, René. A utopia ou a morte.Rio de Janeiro: Paze Terra.

39. LEWTS, John, $O$ homem e a evolugto. Rio de Janeiro: Paz e Terra.

40. LUTZENBERGER, José A Fim de Fuituro? Manifesto ecológico brasileiro. Porto Alegre:Movimento/UFRS.

41. MINC, Carlos. Como fazer mooimento ecológico. Petrópolis: Vozes.

42. SNYDER, Enest. Parem de matar-me Săo Paulo: Nacional

Nota: Sem falar nos Brundtland Bulletins, todos ricos de informacões sobre a questfio ambientalista, alguns dos textos mais atirali$z a d o s$, diretamente ligados à mesma, sấo os seguintes.

- Nosso Futuro comum

- S.O.S. Planeta Terra;

- Sinais de Esperança: lutando

por nosso futuro comum;

- Relatório sobre o Desenvolvimento Mundial - 1992;

- Global Environment - a planet in stress;

- Aquecimento global: o relatório Greenpeace. 